This item was submitted to Loughborough's Research Repository by the author.

Items in Figshare are protected by copyright, with all rights reserved, unless otherwise indicated.

\title{
Lidocaine permeation from a lidocaine NaCMC:gel microgel formulation in microneedle pierced skin: vertical (depth averaged) and horizontal permeation profiles
}

\section{PLEASE CITE THE PUBLISHED VERSION}

http://dx.doi.org/10.1007/s13346-015-0229-z

\section{PUBLISHER}

Springer Verlag / @ Controlled Release Society

VERSION

AM (Accepted Manuscript)

\section{PUBLISHER STATEMENT}

This work is made available according to the conditions of the Creative Commons Attribution-NonCommercialNoDerivatives 4.0 International (CC BY-NC-ND 4.0) licence. Full details of this licence are available at: https://creativecommons.org/licenses/by-nc-nd/4.0/

\section{LICENCE}

CC BY-NC-ND 4.0

\section{REPOSITORY RECORD}

Nayak, Atul, Liam Short, and Diganta Bhusan Das. 2015. "Lidocaine Permeation from a Lidocaine Nacmc:gel Microgel Formulation in Microneedle Pierced Skin: Vertical (depth Averaged) and Horizontal Permeation Profiles". figshare. https://hdl.handle.net/2134/17532. 


\title{
Lidocaine permeation from a lidocaine NaCMC:gel microgel formulation in microneedle pierced skin: vertical (depth averaged) and horizontal permeation profiles
}

\author{
Atul Nayak · Liam Short · Diganta B. Das* \\ Department of Chemical Engineering, Loughborough University, Loughborough LE11 3JX, UK \\ *Corresponding author (Email: d.b.das@lboro.ac.uk)
}

\begin{abstract}
Common local anaesthetics such as lidocaine are administered by the hypodermic parenteral route but it causes pain or anxiety to patients. Alternatively, an ointment formulation may be applied which involves a slow drug diffusion process. In addressing these two issues, this paper aims to understand the significance of the 'poke and patch' microneedle (MN) treatment on skin in conjunction to the lidocaine permeation, and in particular, the vertical (depth averaged) and horizontal (e.g., lateral) permeation profiles of the drug in skin. The instantaneous pharmacokinetics of lidocaine in skin was determined by a skin denaturation technique coupled with Franz diffusion cell measurements of the drug pharmacokinetics. All pharmacokinetic profiles were performed periodically on porcine skin. Three $\mathrm{MN}$ insertion forces of 3.9, 7.9, and 15.7 $\mathrm{N}$ were applied on the $\mathrm{MN}$ to pierce the skin. For the smaller force $(3.9 \mathrm{~N})$, post $\mathrm{MN}$ treated skin seems to provide an 'optimum' percutaneous delivery rate. A 10.2 fold increase in lidocaine permeation was observed for a MN insertion force of $3.9 \mathrm{~N}$ at $0.25 \mathrm{~h}$ and similarly a 5.4 fold increase in permeation occurred at $0.5 \mathrm{~h}$ compared to passive diffusional delivery. It is shown that lidocaine permeates horizontally beyond the area of the MN treated skin for the smaller MN insertion forces, namely, 3.9 and $7.9 \mathrm{~N}$ from 0.25 to 0.75 hours, respectively. The lateral diffusion/permeation of lidocaine for larger $\mathrm{MN}$ treated force (namely, $15.7 \mathrm{~N}$ in this work) seems to be insignificant at all recorded timings. The $\mathrm{MN}$ insertion force of $15.7 \mathrm{~N}$ resulted in lidocaine concentrations slightly greater than control (passive diffusion) but significantly less than 3.9 and $7.9 \mathrm{~N}$ impact force treatments on skin. We believe this likelihood is due to the skin compression effect that inhibits diffusion until the skin had time to relax at which point lidocaine levels increase.
\end{abstract}

Key words: Microneedle, Percutaneous Delivery, Depth averaged permeation, Lateral permeation, Lidocaine, Skin 


\section{INTRODUCTION}

Lidocaine hydrochloride, to be called as lidocaine herein, is a drug which is used as a local anaesthetic for superficial skin wounds [1, 2]. Traditionally, lidocaine is delivered by hypodermic injection for parenteral administration. This causes pain and often trepidation coupled with patient phobia, which may obstruct the successful delivery of the drug [3, 4]. Other traditional methods of lidocaine delivery involve the use of topical ointment (e.g., Anesten ${ }^{\mathrm{TM}}$, Haim International, Seoul, Korea) and transdermal patch (e.g., Lidoderm® patch [5]). However, they have a disadvantage of taking a longer time for the drug to diffuse into the dermis layer through the stratum corneum (SC) layer of skin [6]. In percutaneous lidocaine delivery, the formidable challenge is to bypass the SC. This layer is $10-15 \mu \mathrm{m}$ thick and it is the skin's uppermost barrier to foreign particulate entry into skin $[7,8]$.

In general, the mass flux due to diffusion of drug molecules through the SC is affected by the molecular hydrophilicity and the concentration gradient across different skin depths [9]. Franz diffusion cell (FDC) is typically adopted to determine the in vitro (IV) mass transport properties of the active molecules passing the SC [10] or the whole skin thickness [11,12]. Depending on the direction of concentration gradient and permeability, an active molecule can however diffuse both vertically and horizontally in skin tissues. In the present context, horizontal permeation is taken in a broad sense. It may imply both lateral and transverse permeation in a Cartesian coordinate system or radially for circular co-ordinate system.

The migration of the active molecules due to a concentration gradient from the skin surface is the most commonly accepted IV vertical (depth averaged) transdermal delivery bypassing the viable epidermis (VE) and dermis layer before appearing into the receptor compartments of FDC. In a similar manner, the horizontal permeation of the drug molecules in IV skin biopsy can be a direct technique for quantifying the drug transport in the lateral (x-direction), transverse ( $y$ direction) or radial (r-direction) directions at different distances from an epicentre of the skin (Figure 1a) provided the drug transport can be determined. In the case of MN treated skin, e.g., 'poke and patch' type delivery [13], the origin of a drug can be the outermost (e.g., skin surface) and/or the inner locations of the skin (e.g., microcavity). As far as we are aware, there are few or no studies relating to the migration of a drug molecule in both vertical and horizontal directions in MN pierced skin, and in particular, lidocaine delivery using MNs. This issue can be particularly important for distribution of lidocaine delivered in skin.

Skin can be interpreted as a complex hydrophobic membrane because of the inherent barrier property against most exogenous molecules. In most cases, small, hydrophobic molecules migrate by intracellular and intercellular routes inside skin. At a given time, biopsied sections of 
the skin can be homogenised and denatured for the purpose of disrupting the skin tissue structure and releasing the active molecules into sample vials for determining their concentrations, e.g., analyses using high performance liquid chromatography (HPLC) [14]. The homogenisation and denaturing of skin is discussed further in this manuscript.

In a number of recent studies, it has been discussed that MN assisted percutaneous delivery of lidocaine may be beneficial in numbing a larger surface area of skin and minimising possible clearance from predominate vertical permeation of the drug $[11,12,15,16]$. Parenteral administration of lidocaine may increase the chances of clearance resulting in its depleted levels in the systemic circulation [17]. Lidocaine is metabolised in the systemic circulation by various enzymes, and additional medications such as statins and chemotherapeutic agents can potentially increase the clearance of lidocaine influenced by the metabolism $[18,19]$. Furthermore, the diffusion of hydrophobic and hydrophilic molecules in SC layer has been reported to be faster laterally than vertically across the skin because of the continuous nature of the intercellular pathway [20,21]. As far as we know there is only one reported experimental study on horizontal permeation of lidocaine in full thickness skin [15]. In this study, a method of dip coating MNs with lidocaine and single patch application was attempted. After skin samples were enzymatically digested, it was found that therapeutic thresholds could be sustained for short durations and higher lidocaine concentrations could be obtained for longer durations when combined with a vasoconstrictor epinephrine after treatment with dip coated liquid crystalline polymer MNs [15].

As a drug delivery method, MNs have been reviewed significantly in the literature and therefore they are not discussed in length in this paper [22-24]. The MNs can be constructed from silicon, metals or polymers $[9,22,25]$. In principle, they should pierce past the SC layer to form micro cavities in skin before drug application or pre-loaded with drugs at the point of application. In other cases the MNs dissolve once in the skin releasing the drug to allow increased permeation rates [26]. The resealing time of $\mathrm{MN}$ induced cavities in skin has evoked interest when considering the poke and patch technique [13] and, drug pharmacokinetic thresholds have been found to be affected when pore closure is considered. For example, Brogden et al. [27] expressed the half-life of pore closure from placebo MNs at 18.2 hours and $87.5-97 \%$ of microcavities were closed between 54.7-91.2 hours. In the case of lidocaine application with the help of $\mathrm{MN}$, time duration of 45 minutes to 1 hour may be short in attempting to relate the possible effects on pore closure time with micro-cavity drug permeation; however, there is little or no evidence in this regards at the moment.

Recently, a lidocaine sodium carboxymethyl cellulose/gelatine ( $\mathrm{NaCMC/gel}$ ) bipolymeric formulation has been suggested for controlled permeation of lidocaine in MN pierced skin [11, 
12] where the authors have used a 'poke and patch' approach for percutaneous delivery of lidocaine. Subsequently, the permeation profiles of the MN pierced skin for various mass ratios of $\mathrm{NaCMC/Gel}$ with lidocaine were determined. The MN pierced skin showed faster lidocaine permeation than untreated $\mathrm{MN}$ skin for vertical layer skin profiles. Lidocaine was released into the skin from the formulation and it bypassed the SC layer because of the MN cavities. Furthermore, the physico-chemical properties of the formulations, loading efficiency, zeta potential, mean particle size and morphology have been studied. In principle, the MN treatment of skin allows further increase in the efficacy of lidocaine permeation as well as controlled spreading of the drug formulation along the skin surface as demonstrated in the above studies.

In general, homogenisation of skin adopts mechanical forces of shearing and compression of skin into shredded tissue components. For example, a rotor component of a rotor/stator homogeniser may be used which creates low pressure areas, moving suspension material (e.g., skin tissue debris) towards a sub-500 $\mu \mathrm{m}$ gap between the rotor and stator, shearing any trapped suspension material [28]. However, the adaptation of a rotor/stator homogeniser is unsuitable for shredding dissected thin skin slices below $500 \mu \mathrm{m}$ thickness. This is due to the skin not being properly sheared if it enters and exits the rotor/stator. An alternative homogeniser is a glass tissue grinder (e.g., constructed from Teflon) and comprising of a specialist mortar test tube [29]. Sharp blade based shear homogenisation is not a regular process for skin tissue samples despite not requiring external power sources. An example application of this can be found in cutting of porcine ear tissue before denaturation by dimethylsulfoxide solution (DMSO) [14].

Another method which involves the pestle and mortar skin homogenisation [30] without the need for direct current (DC) or alternating current (AC) supply was adopted in our study. There have been a relatively small number of publications outlining the details of this technique for skin homogenisation prior to drug quantification in skin layers. Conceptually, the method aims to increase the amount of ruptured cells and dissemble the organised cell packing in skin tissues randomly. There is a likelihood of tissue sections that have not been exposed to sufficient shear forces. Therefore, this alone cannot suffice for the purpose of drug detection and, hence, a second step of cellular denaturation is required to release the drug molecules for subsequent detection. The second stage of enzymatic protein denaturation of skin specimens are outlined in examples of quantification of hydroxyproline as a byproduct of $\alpha$-chymotrypsin hydrolysis from fragmented collagen [31] and the quantification of combined chemical enhancers such as 5aminolevulinic acid with glycerol monooleate in epidermal skin delivery [32]. However, diode array detection and peak area quantification of active macromolecules eluting at similar detection wavelengths ranges to enzyme and skin protein by products is unachievable by liquid 
chromatography-diode array (LC-DA) analysis alone. Therefore, heat denaturation technique may be used.

High temperatures above $50^{\circ} \mathrm{C}$ for a long period allow for intra and extracellular denaturation of skin proteins [33]. Denaturation temperature of human skin at $38.5^{\circ} \mathrm{C}$ allows the appearance of imino acid residues in protein breakdown (222 imino residue parts per 1000 part amino acids) [34]. Collagen based porcine skin has a denaturation temperature of $37^{\circ} \mathrm{C}[35,36]$. Also, dry heating (e.g., a thermal effect generated by passing hot air) at temperature ranging from $100^{\circ} \mathrm{C}$ to $315^{\circ} \mathrm{C}$ on skin surfaces result in the weakening of mechanical properties and disorder of keratin network of the skin [37]. Adaptation of dry heat ablation of skin at high temperatures occurred during micro second time frames as longer durations would have denatured more skin proteins below the upper layers [37]. Also, prolonged dry heat ablation would burn skin into powdered carbon ash and lidocaine will be undetectable by LC-DA methods as the chemical structure would be changed completely.

Keeping the above discussed points in mind, lidocaine permeation rates have been analysed in the vertical and horizontal directions in this paper specifically for lidocaine $\mathrm{NaCMC/gel}$ bipolymeric formulation. Alternatively to Zhang et al. [15] enzymatic denaturation technique, homogenisation followed by heat denaturation of the IV skin biopsy was performed to determine the horizontal permeation profile in the MN pierced skin (discussed below) while FDC was used to determine the vertical permeation profiles. For the purpose of this work a 'poke and patch' technique was adopted using fixed MN insertion forces $[23,25,38]$ with the purpose to obtain reproducible artificial microcavities and to enhance the percutaneous lidocaine delivery in bypassing the SC layer of skin. Constant MN insertion forces from a pneumatic pressure based force device are applied and held for fixed time duration to allow the MNs to pierce the skin as uniformly as possible [23]. This also ensures that the MN cavities are formed so as to just pierce past the SC providing small MN holes for percutaneous drug delivery.

In the context of this paper, we aim to relate the effects of $M N$ insertion forces with the instantaneous pharmacokinetic distribution of lidocaine towards vertical (depth averaged) and horizontal permeation in skin. Ideally, the lag time for therapeutic level of lidocaine permeation needs to be the shortest possible for affecting the skin target region. Nevertheless, a sustained therapeutic level for upto 45 minutes is considered to be most ideal in numbing the area, for example, in the treatment of skin wounds or localised biopsy of abnormal skin tissue. Procedures such as ablative skin resurfacing requiring at least 60 minutes for uniform anaesthetic effect can potentially be shortened to 45 minutes duration maximum for regaining complete local sensation in the area and reducing patient waiting time [39]. Within this work, a method of measuring the vertical diffusion coefficient through porcine skin is also attempted. 
This required first, the use of a FDC followed by centroid and diametric from centroid punching of the square sectioned skin which were subsequently homogenised mechanically and heat denatured.

It is expected that this paper would allow better understanding of vertical and horizontal permeation of lidocaine in MN pierced skin.

\section{MATERIAL AND METHODS}

\section{Materials}

Gelatin (Porcine, type A, Bloom 300), sodium carboxymethylcellulose (degree of substitution 0.9; $\mathrm{MW}: 250 \mathrm{kD}$ ), lidocaine $\mathrm{HCl}$ (MW: $288.81 \mathrm{~g} / \mathrm{mol}$ ), sorbitan monooleate (SPAN 80), Glutaraldehyde (stock solution of $50 \% \mathrm{w} / \mathrm{w}$ ), trifluoroacetic acid (>99 \% assay) and paraffin liquid (density: $0.859 \mathrm{~g} / \mathrm{ml}$ ) were purchased from Sigma-Aldrich Ltd, Dorset, UK. Acetonitrile (HPLC grade, $99.8 \%$ assay) and acetic acid (analytical grade, $99.8 \%$ assay) were purchased from Fisher Scientific Ltd, Loughborough, UK). Essential materials for IV skin studies were porcine auricles (local butcher, Loughborough, UK), stainless steel MNs (AdminPatch $₫ 1200$, nanoBioSciences PLC, California, USA) and FDCs (Logan Instruments Inc, 'FDC-6', New Jersey, USA) were already available.

\section{Preparation of Lidocaine NaCMC:gel microgels}

The optimum Lidocaine NaCMC:gel 1:2.3 microgels were prepared exactly as outlined from the methods stated in Nayak et al. [11]. The reason for choosing NaCMC:gel 1:2.3 as the optimum vehicle was due to the ideal physico-chemical properties outlined in Nayak et al. [11].

\section{Percentage loading efficiency}

The characterised percentage loading efficiency (LE) for our lidocaine microgel formulation (equation 2) was calculated as discussed earlier [11,12]

$\% \mathrm{LE}=\frac{\text { Actual } 5 \% \text { weight of Lidocaine from sample }(\mathrm{g})}{5 \% \text { theoretical loaded weight of Lidocaine }(\mathrm{g})} \times 100$

A $5 \%$ of the mean total sample weight was used to save time in preparation of new batches of formulation for one set of tests. Lidocaine microgels formulated on a batch scale was a time consuming process and complete samples were not tested here. The lidocaine hydrogels were diluted with $20 \mathrm{ml}$ of ultrapure water as excess solvent heated to $40 \pm 0.5{ }^{\circ} \mathrm{C}$ and sonicated (Branson Digital Sonifier 450, USA) at 15-20 W for 2 minutes. This allows lidocaine to dissolve in ultrapure water. Normal sonication frequencies cut approximately 24 hours' maximum time 
required to disrupt the electrostatic and covalently held microparticle interactions between $\mathrm{NaCMC}$ and gel by high temperature denaturation without boiling the drug [40]. The 'dissolved lidocaine' was filtered using Nylon 6,6 membranes of $0.1 \mu \mathrm{m}$ pore size (Posidyne membranes, Pall Corporation, Portsmouth, UK) before quantification by HPLC analysis.

\section{Microgel morphology and microparticle diameters}

The morphology of lidocaine NaCMC:gel 1:2.3 microgels were observed under an optical microscope (Olympus BX43, Tokyo, Japan). Images of the microparticles were taken using a camera (Q imaging Retiga 2000R, Canada) and analysed using ImageJ software.

\section{In vitro permeation studies}

The amounts of lidocaine in the VE layer and systemic layer (receptor of FDC) were determined from IV studies. The pharmacokinetics was subsequently deduced from IV quantification for vertical and horizontal permeation of lidocaine assuming homogeneity of the VE layer for molecular diffusion, i.e., isotropic diffusion profiles [41].

\section{Skin preparation}

As recommended in Meyer et al. [42], whole porcine auricle squares of $4.0 \mathrm{~cm}^{2}$ were laterally thin sliced and the cartilage, connective tissue and fatty components were discarded. All visible hair was removed using scissors to minimise any obstruction with the placement of lidocaine microgel on skin. MNs (AdminPatch $\left.{ }^{\circledR} 1200\right)$ were applied on the skin for upto 5 minutes. Each needle was preset to $1100 \mu \mathrm{m}$ length with a MN density of 43 in one $\mathrm{cm}^{2}$ surface area. MNs fabricated at $1000 \mu \mathrm{m}$ length have the same pain scores (VAS) on human subjects in comparison to the borosilicate glass material extruded at $500 \mu \mathrm{m}$ length when a saline volume of upto $0.6 \mathrm{ml}$ was delivered in the dermis layer of skin [43]. Normally, the entire length of MNs from base to tip does not penetrate the skin with the needle base touching the skin surface because of the elastic folding effect of skin [9]. A full thickness skin piercing using $1100 \mu \mathrm{m}$ length MNs and the MNs density resulted in approximately $400 \mu \mathrm{m}$ deep cavities [12]. However, we controlled the MN cavities to a much smaller length so as to just pierce the SC in this work as discussed below.

\section{Application of MN insertion force}

In order to ensure that uniform force is applied to pierce the skin, the MN patch was applied on the skin samples at $0.5,1.0$ and 2 bar pressures equating to forces of 3.9, 7.9 and $15.7 \mathrm{~N}$, respectively. The minimum insertion force achievable using an in-house pressure/force device 
[23] was 3.9 N. The three insertion forces adopted here were constant forces as a hypothetical standard if an applicator device were to be fabricated to insert the MNs into skin. Thumb pressure, as often done to insert MN on skin, was not applied as they may introduce some variability in the forces applied. Furthermore, the forces were chosen so as to just pierce the skin keeping in mind the percutaneous delivery of lidocaine where the MNs cavities are small rather than large which facilitate transdermal permeation of the drug.

The insertion forces were applied via a vertically arranged pressure/force impact device (SMC pneumatics Ltd, Buckinghamshire, UK; serial: CD85N16-50-B) as adopted from Cheung et al. [20]. The insertion force was calculated using equation (1):

$$
F=\frac{p \pi d^{2}}{4}
$$

Where $F$ is the force $(N), p$ is the pressure $\left(N / \mathrm{mm}^{2}\right)$, and $d$ is the piston bore diameter $(\mathrm{mm})$. As the piston rod is lowered far down the cylinder compartment so that the punch unit touches the MN substrate, the outstroke impact of a double acting cylinder is the dominating force in a double acting pressure device [44]. Independent air pressures at 0.5-2 bar ranges were impacting on the bore area of the lowered piston rod. The bore area was contained inside a closed piston chamber so that compressed air could not escape the piston chamber and impact the tissue directly. Therefore, equation (1) is implemented in determining the vertical compression force.

\section{Dyeing of skin samples}

Skin samples were dyed to show qualitative MN piercing patterns through skin in plan (top) view as a quick method to determine if MNs have pierced the skin. As in IV studies, the device outlined by Cheung et al. [23] was used to treat skin samples at 3.9, 7.9 and $15.7 \mathrm{~N}$ for upto $5 \pm$ $0.1 \mathrm{~min}$. Samples were observed after dyeing with a natural blue food colouring (Sainsbury's, Loughborough, Leicestershire, UK ).

\section{Characterisation of microcavities}

Similar MN impact forces and time taken as mentioned in the previous section were subjected on the skin samples. The largest cross sectioned row of channels was viewed by microdissecting strips in plane to $\mathrm{MN}$ path as shown in Figure 1b. An image of a MN patch (AdminPatch ${ }^{\circledR}$ ) adopted for the poke and patch method throughout this study is shown in Figure 1c. The samples were then cryotomed $(5 \mu \mathrm{m})$, dyed in methylene blue solution $(0.5 \% \mathrm{w} / \mathrm{v})$ (Sigma Aldrich, Dorset, UK), observed under the microscope (Ceti S035, Chalgrove, 
Oxfordshire, UK) and scaled using an image processing software (ImageJ, National Institute of Health (NIH), USA) with a certified graticule. Unlike in the previous method of using proprietary food colouring, the distinct blue colour density between SC and VE layer can only be observed by methylene blue dye. Methodology for this was adapted from Chueng et al. [23]. Additionally, flash freezing was adopted to preserve pierced holes created as compared with slow 24 hour freezing at $-30^{\circ} \mathrm{C}$ in a cryotome.

As stated above, the SC layer is accepted to be the topmost (first) $\sim 15 \mu \mathrm{m}$ thick skin layer in accordance with literature (e.g., Sivamani et al. [8]). It was also confirmed by dissecting $5 \mu \mathrm{m}$ transverse slices of skin and studying under the microscope after dying the skin surface with methylene blue solution ( $0.5 \% \mathrm{w} / \mathrm{v})$ (Sigma-Adrich Ltd, Dorset, UK). The recommended concentration of methylene blue solution and the approximate time in allowing dye diffusion through skin was adopted from Singh and Banga [45] and Kalluri and Banga [46].

\section{Permeation Study}

Lidocaine permeation studies were performed using MN treated skin, which were compared with passive permeation profiles of the drug. Lidocaine NaCMC:gel 1:2.3 microgel $(0.1 \pm 0.02 \mathrm{~g})$ droplet was added on an epicentre skin surface before clamping onto a FDC (FDC-6). The amount of lidocaine loaded in the microgel was $2.44 \%$ wt. The surface area of the FDC receptor orifice was $0.679 \mathrm{~cm}^{2}$. Lidocaine formulations were dispensed on the epicentre of the skin (Figure 1a) [11,12]. The receptor compartment of the FDC contained deionised (DI) water set at $37 \pm 0.5^{\circ} \mathrm{C}$ in order to mimic physiological temperature in of plasma rich systemic layer. The total receptor volume was $5.0 \pm 0.025 \mathrm{ml}$. Receptor volumes $(1.5 \pm 0.5 \mathrm{ml})$ were removed at 0.25 hour intervals. The total duration of IV study was one hour. After the FDC experiments, the epicentre and diametrically opposite regions of the skin was biopsied (Figure 1a) (RS International, Nottinghamshire, UK). The epidermis of punched skin was temporarily bonded using Cryo-M-bed inert glue (Bright Instrument Company Ltd, Cambridgeshire, UK) onto prechilled sample holders frozen in a cryotome $\left(-30^{\circ} \mathrm{C}\right)$ for 30 minutes (Bright Instrument Company Ltd, Cambridgeshire, UK). Horizontal SC layer micro dissection followed and first $15 \mu \mathrm{m}$ thick layer was accepted as the SC layer [47] with the remaining skin layer saved as VE for lidocaine quantification. The VE and dermis boundary was not possible to separate accurately as compared to the SC and VE boundary by cryotome dissection.

The depth resolved mass transfer of lidocaine through the skin involved treated skin samples separated into the VE and systemic layer as clearance. The SC layer was discarded because the amount of lidocaine was found to be inconclusive and, we are primarily interested in the 
permeation from the micro-cavities created by the MNs. There is a likelihood of parts per billion amounts of lidocaine that cannot be traced by HPLC-DA methods as adopted in this work.

The VE samples were homogenised in a pestle and mortar containing pipetted $1.5 \pm 0.03 \mathrm{ml}$ deionised (DI) water (ThermoFisher Scientific, Loughborough, Leicestershire, UK) before being denatured in a water bath (Nickel-electro Ltd, Somerset, UK) at $60^{\circ} \mathrm{C}$ for 1.5 hours. Conceptually, lidocaine hydrochloride readily dissolved in the excess solvent water due to the thermolabile nature of proteins and onset of denaturation at $40^{\circ} \mathrm{C}$ [48].

After centrifugation at $4443 \mathrm{~g}$ (8500 rpm) (Eppendorf Minispin, Hamburg, Germany), the supernatant was filtered using Polyethersulfone (PES) membranes (Pall Life Sciences, Portsmouth, UK) with a trapping MW of $1 \mathrm{kDa}$ in preventing excess skin proteins and polypeptides contaminants accumulating with the released lidocaine. HPLC (Perkin Elmer 1200, Abingdon, Oxfordshire) protocol was then implemented to analyse the lidocaine allowing deduction of permeation kinetics [12]. This study was performed in triplicate. In addition to the IV studies undertaken, several synergistic characterisations were performed as discussed in the subsequent sub-sections.

\section{Determination of lidocaine diffusion in skin (D)}

The exploration of lidocaine diffusional pharmacokinetics such as apparent diffusion coefficient and permeation flux are obtained from Fick's diffusion law as shown in equation (3) in mass terms.

$J=-D_{i m} \frac{d C_{i}}{d x}$

where $\mathrm{J}$ is the diffusion flux (mass $/ \mathrm{cm}^{2} / \mathrm{s}$ ), $D_{\text {im }}$ is the diffusion coefficient of species $i$ in the skin $\left(\mathrm{cm}^{2} / \mathrm{s}\right), \mathrm{C}_{\mathrm{i}}$ is the concentration of active molecule, $i\left(\mathrm{mass} / \mathrm{cm}^{3}\right)$ and $\mathrm{x}$ is the thickness of membrane, skin (cm). When MNs are inserted to pierce of skin the concept is to increase the diffusion coefficient $D_{\text {im }}$ effectively so that there is an increase in mass transfer through the SC into the VE layer. If this is achieved, MN 'poke and patch' would decrease the dependence on hypodermic needles and improve on the current use of creams.

For an infinite donor solution, the concentration of active molecules in a drug vehicle is constant and can be expressed as in equation 4. The infinite donor method describes a practice of dispensing the drug on the donor area for increased reproducibility [49]. In this case, the source of the lidocaine is from NaCMC:gel microgels [11,12]. 


$$
J=\frac{D_{i m} K}{x} C_{i}
$$

Where $\mathrm{K}$ is the drug's partition coefficient between the vehicle and SC or VE layer, $\mathrm{x}$ is the drug diffusion path length [50]. Graphically, the cumulative amount of active molecule or drug permeated is plotted against time and the linear region of the slope in a polynomial based function graph is the permeation rate of drug at steady state [50]. Due to the insignificant number of nociceptive receptors in the SC layer, the VE and dermis (D) are defined as the target layers where lidocaine is required for effective anaesthetic action. A minimum therapeutic lidocaine concentration of $1.5 \mu \mathrm{g} / \mathrm{ml}$ [51] is defined to be necessary in the VE and dermis layers for this to be the case. Separating the VE layer from the dermis is only possible through histological detection of the boundary between cell morphological changes. As mentioned earlier, the VE and dermis layer cell boundaries could not be detected uniformly and efficiently. The dermis layer skin thickness can vary from 200 to $350 \mu \mathrm{m}$ [52]. However, there is no distinct, fast procedure for VE and dermis layer boundary identification, followed by micro dissection according to fundamental histological changes in strata.

\section{RESULTS AND DISCUSSIONS}

\section{Effects of insertion forces on MN cavities in skin}

As we mentioned earlier, we controlled the $\mathrm{MN}$ insertion forces directed on the skin surface to ensure reproducible and minimum variability of path lengths for the cavities. MN impact forces ranging from $3.9-15.7 \mathrm{~N}$ were used in this work. All forces were applied for five minutes durations and, in each case, the MNs pierced skin (Figures 2 and 3). In the figures, the dark blue spots were due to liquid dye pooling and increased diffusing into the MN micro cavity's viable strata. The skin images did not show all of the MNs that had punctured the skin at $90^{\circ}$ to a horizontal plane, as in a small number of cases the regular array triangular based pattern could not be identified (Figure 3). This effect was caused by needles not entering into the skin vertically due to the elastic nature and inherent roughness of the skin.

The SC layer emerged as a dark blue band along a transverse slice of skin as highlighted by a yellow line (Figure 3). Initial dissecting of skin at $15 \mu \mathrm{m}$ thickness showed some blade skin stretching due to the applied shear forces resulting in some SC thicknesses greater than $30 \mu \mathrm{m}$. Thinner transverse slices at $5 \mu \mathrm{m}$ minimised any substantial blade stretching. An average SC thickness of $18.6 \mu \mathrm{m}$ was deduced. Although this is marginally larger than the $15 \mu \mathrm{m}$ conventional depth taken in IV studies, it was decided that due to the likelihood of minor blade stretching of the skin during dissection, the $15 \mu \mathrm{m}$ would be retained as the average thickness of the SC in this study as mentioned in several literature sources. Blade stretching effects on 5 
micron sliced skin was fairly evident when compared with a $15 \mu \mathrm{m}$ sliced skin that resulted in up to $33 \mu \mathrm{m}$ SC layers. This means that the insertion forces should be designed so as to enable the MNs to pierce $15 \mu \mathrm{m}$ on top of the skin.

After analysis of the skin samples $(n=6)$ corresponding to each $M N$ insertion force, the average cavity lengths corresponding to each $\mathrm{MN}$ insertion force are calculated which are shown in Figure 4. As expected, increasing the force increases the path length. A direct proportionality relationship between the insertion force and cavity length (e.g., doubling the force resulting in a doubling of cavity length) was not observed. The cavity length increased $18.4 \%$ and $15.8 \%$ from 3.9 to 7.9 and 7.9 to $15.7 \mathrm{~N}$, respectively. This suggests that increasing force decreases potential cutting effect through the skin. This is likely caused by a resultant force skin compression effect from the excess perpendicular force on the skin. As the skin compresses it may become more dense (e.g., higher viscoelasticity) and harder to penetrate deeper into the skin. In fact, the increasing force may cause more deformation of the skin. This may cause the entering needles to buckle and therefore they may be unable to penetrate as deeply as expected into the skin. Other factors have been shown to affect the size of cavities that can be made by MNs such as the viscoelasticity of the microgels filling the cavities. This is discussed further by Cheung et al. [23].

\section{Optimum lidocaine NaCMC/GEL 1:2.3 microgel}

A favourable mass ratio microgel vehicle according to strong physicochemical interactions between $\mathrm{NaCMC}$ and gelatine was chosen for this study. As this paper focuses on a distinct area of permeation pharmacokinetics, any further microgel based optimisation studies were not sought after in this work. The optimum gel to NaCMC mass ratio of 2.3 for lidocaine derives from the previous studies on zeta potential and particle sizes by Nayak et al. [11]. This section expresses comparisons with particle morphology and outlines the challenge in controlling the loading efficiency of microgels. Lidocaine NaCMC/GEL 1:2.3 microgels were observed to be spherically defined and polydisperse (Figure 5).

An average of $53 \%$ loading efficiency was deduced for lidocaine loading. In comparison to Nayak et al. [11] this was slightly higher. The observed microparticles range was 1.7-8.0 $\mu \mathrm{m}$ (Figure 5) in this work had a smaller range than in Nayak et al. [11] which would contribute a greater loading efficiency because of larger microparticle surface areas (Figure 5). The polydispersity of the applied formulation was less than that in Nayak et al. [11] because the difference in microgel diameter was $15 \mu \mathrm{m}$ compared with our current study of $6.3 \mu \mathrm{m}$ microgel diameter. No focus was given in controlling and reducing the microgel polydispersity in this work because the reduction in gelation and increase in covalent crosslinking concentrations such as 
glutaraldehyde in the formation of polymeric microparticles may alter the current hydrogel properties of the formulation.

\section{Vertical percutaneous lidocaine permeation}

The trend on the effects of MN insertion force, cavity depths and permeation of lidocaine vertically (depth averaged) through the skin are discussed in this section. The VE layer is the main focus for lidocaine permeation because we consider this to be the target region in skin. It seems that a small force such as an $\mathrm{MN}$ impact force of $3.9 \mathrm{~N}$ was the most favourable for lidocaine permeation through the vertical VE layer. A 10.2 fold increase in permeation was observed for a $3.9 \mathrm{~N}$ force at $0.25 \mathrm{~h}$ and similarly a 5.4 fold increase in permeation occurred at $0.5 \mathrm{~h}$ compared with passive diffusional permeation (Figure 6a).

The lidocaine permeated in the VE layer for 7.9 N and 15.7 N MN treated skin was less than the $3.9 \mathrm{~N}$ treated skin. This result at first may appear to be a contradiction to increasing trends because the longer the cavity path length, the shorter time and greater concentration of drug in reaching the VE layer. However, we believe that the elasticity of the skin causes a cushioning effect for the MN arrays and higher MN insertion force does not necessarily allow the whole set of MNs in the array sequence to penetrate the skin at double or treble depths of proportional MN force (Figures 2 and 4). This could be worsened by a 'bed of nails effect' in which the MNs are close enough together to spread the force causing it to compress the skin rather than penetrating it. Once compressed, the diffusion coefficient $\left(D_{\text {im }}\right)$ (equation 3 ) of the skin could be decreased, making it more difficult for the molecule to diffuse through the skin despite the increased path length [53].

The error bars representing standard deviation outline good reproducibility, especially for the MN permeation results up to $t=0.75$ hours (samples $n=3$ ) (Figure 6). Overall, for the MN chosen, the smallest force (i.e. the force of $3.9 \mathrm{~N}$ ) showed a more favourable transient permeation profile because of substantial increases in lidocaine in the VE layer epicentre and a slight plateau effect emerging just after $0.5 \mathrm{~h}$ (Figure 6a). The largest $\mathrm{MN}$ insertion force, namely, $15.7 \mathrm{~N}$, also shows a favourable transient profile with respect to a plateau appearing after $0.25 \mathrm{~h}$ but the amount of lidocaine permeated in the VE layer is 2.0 and 2.8 folds less than the amounts observed for $3.9 \mathrm{~N}$ at timings of 0.25 and 0.5 hours, respectively (Figure 6a).

The main target skin layer for local anaesthesia is the VE layer as outlined in the introduction. Figure 7 outlines the instantaneous lidocaine permeation profile in blood plasma clearance, namely, the receptor cell of FDC $(n=3)$. The Grubb's test [54] identified outliers from pooled data 
sets and all outliers were eliminated. A coefficient of variance (CoV) identified other possible random errors (equation 5):

$\mathrm{CoV}=\mathrm{SD} / \overline{\mathrm{x}}$

Where SD is standard deviation and $\bar{x}$ is the arithmetic mean of data points. A threshold of upto $30 \%$ CoV was taken to justify disregarding any data that caused significant increases in SD. The lowest CoV values were taken in triplicate. In cases where results were seen to be anomalous, it was likely to be caused by errant skin proteins that partially denatured or passed through the pores of the ultrafine PES membranes during the released drug filtration stage (permeation study section). The concentration of lidocaine $(\mu \mathrm{g} / \mathrm{ml})$ detected in the epicentre VE layer was converted to permeation based concentrations $\left(\mu \mathrm{g} / \mathrm{cm}^{2}\right)$ using equation (6), which were subsequently used to compute the diffusion coefficients according to equation 4

$\mathrm{C}_{\mathrm{p}}=\frac{\mathrm{CsV}}{\mathrm{A}}$

Where $C_{p}$ is the concentration of lidocaine permeated $\left(\mu \mathrm{g} / \mathrm{cm}^{2}\right), C_{s}$ is the concentration of lidocaine $(\mu \mathrm{g} / \mathrm{ml})$ contained in $\mathrm{DI}$ water as the extraction volume $\mathrm{V}(\mathrm{ml})$ and $A$ is the surface area of the punched skin $\left(\mathrm{cm}^{2}\right)$.

In the VE layer of skin, all three MN insertion forces (3.9-15.7 N) (Figure 6b) helped bypassing the minimum lidocaine therapeutic level of $1.5 \mu \mathrm{g} / \mathrm{ml}$ [51]. This was achieved in a small fraction of 15 minutes despite the control samples appearing to reach that level slightly longer. On a dry skin surface, the likelihood of slow passive diffusion is a balance in stability between electrostatic interactions of polymers, lidocaine and covalent Schiff's base interaction by glutaraldehyde [11]. With improved formulation giving a greater concentration gradient this may allow therapeutic levels to be reached in a relatively short period of time.

The permeation of lidocaine into the clearance plasma compartment showed favourable trends for all three MN insertion forces and control within 0.75 hours (Figure 7 ). The smallest force of 3.9 $\mathrm{N}$ showed the lidocaine crossing over the toxic plasma level of lidocaine $(5 \mu \mathrm{g} / \mathrm{ml})$ at a time of nearly one hour. Usually a range of 5 to $10 \mu \mathrm{g} / \mathrm{ml}$ is considered to be a toxic concentration for lidocaine in blood plasma [55].

\section{SC layer permeation}

The SC layer has the potential to bind certain drug molecules despite not being a target region of lidocaine and other local anaesthetics. It is fairly important to outline if a significant amount of lidocaine has remained in this layer, and if not, it can then be defined that the applied lidocaine 
has permeated into the lower skin layers [12]. In this work, the SC layer contained no lidocaine, irrespective of instantaneous MN treatment or PD. The results of numerous 'no result' and occasional very small $\left(\sim 60 \mathrm{E}-5 \mu \mathrm{g} / \mathrm{cm}^{2}\right)$ lidocaine detected in the SC lead to CoV $>30 \%$ and also high standard deviations of the results. In any case, the SC layer concentration detected and amount permeated retained in the SC was taken as negligible. Although the SC layer is the major barrier to diffusion into the skin, it does not retain large quantities of hydrophilic molecules in the present context. The rate limiting step appears evident in passive diffusion of lidocaine into the VE layer as there is a 5.2 fold permeation decrease at $0.25 \mathrm{~h}$ as compared to MN $15.7 \mathrm{~N}$ treated skin. However, due to the lack of nociceptive receptors, anaesthesia will not be affected by this and minimum therapeutic levels as stated in the introduction are non-applicable. For this reason, the SC layer permeation will not be discussed further within this paper.

\section{Horizontal permeation of lidocaine in VE layer}

The horizontal permeation for lidocaine was depicted as a square apex in the VE layer which is outlined and explained according to MN treated skin. The mass transfer of lidocaine was expressed from knowing the mass released for lidocaine in excess DI water. The lidocaine concentration and mass transfer observed were deduced as favourable with respect to crossing the minimum therapeutic levels. The minimum therapeutic level of lidocaine is reported to be $100 \mu \mathrm{g} / \mathrm{g}$ by Zhang et al. [15].

The aim is to understand the shortest possible lag time for horizontal permeation of lidocaine. The horizontal permeation colour charts of lidocaine permeating at a maximum distance of $1 \mathrm{~cm}$ from the epicentre were outlined as localised concentration (Figure 8) and mass transferred (Figure 9). Both figures outline completely different minimum therapeutic level trends for lidocaine observed in the VE layer. The mass of lidocaine was computed according to equation 7.

$M=\frac{C_{s} V}{M_{t}}$

The coefficients $C_{s}$ and $V$ are the same as in the numerator for equation 6 . In the denominator, $M_{t}$ is the calculated mass of lidocaine released from the NaCMC:gel 1:2.3 vehicle from known periodic timings from controlled release studies [11]. Full skin thicknesses were an average 670 $\mu \mathrm{m}( \pm 50 \mu \mathrm{m})$ thick.

When considering the concentration of lidocaine permeated in VE layer, all regimens including control showed horizontal permeation at minimum therapeutic levels (Figure 8). A more substantial concentration of horizontal permeation was observed for the smallest MN insertion 
force $(3.9 \mathrm{~N})$ from 0.25 to 1 hour. This is because the same concentration range was observed for all four corners of the permeation square. The second most favourable horizontal permeation trend was observed for control as concentration equal to or greater than $10 \mu \mathrm{g} / \mathrm{ml}$ was sustained from 0.50 to 1 hour. However, as expected the horizontal permeation in skin for 3.9 and $7.9 \mathrm{~N}$ forces showed greater drug concentrations in three to four corners of a square as compared with control (Figure 8).

The mass transfer of lidocaine horizontally is favourable for MN treated skin at 3.9 and $7.9 \mathrm{~N}$ because of high distributions of lidocaine from 0.25 to 0.75 hours. Unlike the previous concentration based colour profiles (Figure 8), the horizontal diffusion (control) and permeation of lidocaine (MN treated $15.7 \mathrm{~N}$ ) showed below therapeutic mass transfers of lidocaine (Figure 9). Usually lidocaine administered by injection potentially results in faster permeation dependent on injection depth which is variable, initial drug volume from average loading dose of solution and pressure related liquid flow rates into site of delivery $[15,43]$. The injection of $0.6 \mathrm{~mL}$ or greater volume of a fluid such as saline requires applied pressures greater than $1000 \mathrm{mmHg}$ [43].

The poke and patch method used in this study allows the pseudoplastic microgel drug to permeate into the micro cavities by pooling and without the need of flow. In a similar lateral based study by Zhang et al [15] the lidocaine mass transfer was maintained successfully for upto 15 minutes and two biopsied areas from a total of three showed therapeutic levels when considering a distance of $1 \mathrm{~cm}$ from the epicentre and full thickness skin up to $4000 \mu \mathrm{m}$.

\section{The partitioning, flux rate and diffusion coefficient of VE layer for lidocaine permeation}

The pharmacokinetics relating to the permeation of lidocaine affected by the MN treatment at the chosen forces is outlined and explained in this section. It is evident that lidocaine concentration for $3.9 \mathrm{~N}$ insertion force increases after 0.25 hours as the VE layer concentration is increased. This is because the concentration gradient is the driving force for mass transfer into the clearance layer. In the last 0.25 hours of the experiment the lidocaine is permeating into systemic circulation at a greater concentration than in any previous time interval (Figure 7).

The $\mathrm{MN}$ assisted permeation of lidocaine at the small $(3.9 \mathrm{~N})$ and medium $(7.9 \mathrm{~N})$ forces outline increasing partition coefficients $(\mathrm{K})$, especially $3.9 \mathrm{~N}$ treated samples as more lidocaine is detected in the skin than the bipolymeric vehicle (Figure 10). Nevertheless, all three MN pierced skin samples outlined $\mathrm{K}$ for lidocaine to be significantly greater than the control samples. Normally $\mathrm{K}$ is deduced at observed steady state regions of charts at specific time duration in order to derive a constant $\mathrm{K}$ value as a point of reference. We define pseudo steady state at 
smaller time step, and $\mathrm{K}$ values were calculated for different time (Figure 10). At a time over $0.75 \mathrm{~h}$ the maximum partition, $\mathrm{K}$ of 0.58 was deduced for the $3.9 \mathrm{~N}$ treated samples as compared with other treatment technique (Figure 10). Drug based partition coefficients are normally fractions because the vehicle drug loaded mass is greater than the drug in a defined layer of skin.

The lidocaine permeation flux outlines a very consistent increasing trend for $3.9 \mathrm{~N}$ treated skin than control and $15.7 \mathrm{~N}$ treated VE layer of skin (Figure 11a). As expected the flux was a lot higher for $3.9 \mathrm{~N}, 7.9 \mathrm{~N}$ and 15.7 N MN treated VE skin than control (Figure 11a). Comparatively the 3.9 N MN treated VE skin resulted in flux values of 13.9 and 10.5 folds greater than control at times of 0.25 and 0.50 hours (Figure 11a). This is because of lidocaine bypassing the rate limiting SC layer of MN treated skin and diffusing through the VE layer faster. The permeation flux for all treatment regimens in the clearance layer of skin show lower lidocaine flux rates from 0.25 to 0.75 hours (Figure $11 \mathrm{~b}$ ). The permeation flux for $7.9 \mathrm{~N}$ treated skin show significantly greater clearance levels than control, 3.9 N and 15.7 N treated skin (Figure 11b). The likelihood is because of horizontal permeation as observed previously otherwise clearance flux rates would be just as high as VE layer flux when considering vertical permeation alone.

The apparent diffusion coefficient derived from rearranging Fick's first law in terms of coefficient $\mathrm{D}$ was taken from equation 4. Assuming pseudo steady state conditions, the $3.9 \mathrm{~N}$ treated VE layer outlines high lidocaine apparent $D$ with good consistency as compared with control and 15.7 N (Figure 12). A relatively high lidocaine apparent $D_{m}$ of $0.02 \mathrm{~cm}^{2} / \mathrm{h}$ was observed for 15.7 VE treated skin at $t=0.75$ hours which corresponds to the highest flux of lidocaine permeated (Figure $11 \mathrm{a}$ and 12). Like $\mathrm{K}$ based profiles (Figure 10), $\mathrm{D}$ is deduced at observed steady state in deriving a constant $D$ value for reference.

\section{Conflict of Interest}

The authors declare that there is no conflict of interest for this paper.

\section{Conclusion}

The initial assumption of a $15 \mu \mathrm{m}$ deep SC layer was confirmed as acceptable when examining the SC layer under microscope image gave an average of $18.6 \mu \mathrm{m}$. Therefore the experimental value is in close agreement with the commonly accepted average depth of $15 \mu \mathrm{m}$. Transverse skin slicing showed that even the lowest pressure of MNs impact penetrated the skin rather than simply deforming it. The initial premise that increasing the pressure, and therefore the force on 
MN treatment, was confirmed when cavity length studies showed approximately 18 and 16\% increases from 3.93 to 7.85 to $15.71 \mathrm{~N}$.

In vitro studies of lidocaine diffusion gave slight mixed results as compared to passive diffusion; the samples treated with $\mathrm{MNs}$ at $3.9 \mathrm{~N}$ force had consistently larger concentrations of lidocaine in the VE layer. There was a steady increase in this concentration beyond 0.5 hours, showing a significantly high mass transfer drug permeation at this time. Also the increasing partition coefficient trend at increasing time for 3.9 N MN treated skin, VE layer, is very favourable for lidocaine bipolymer. In comparison to conventional creams this is a great improvement and with an improved formulation or a MN array that does not suggest the 'bed of nails' effect.

The horizontal permeation of lidocaine from adopted regimens of passive diffusion to $\mathrm{MN}$ assisted $15.7 \mathrm{~N}$ treatment. All regimens show complete favourable trends at therapeutic level above $1.5 \mu \mathrm{g} / \mathrm{ml}$ solely for direct concentration results without further calculations with lidocaine controlled release adjustments in obtaining mass transfer profiles. The passive diffusion and a higher $\mathrm{MN}$ insertion force $(15.7 \mathrm{~N})$ are the most unfavourable regimens for horizontal permeation based transfer of lidocaine in VE layer. This is because the mass transfer of lidocaine is below the minimum predicted therapeutic mass transfer for local anaesthesia in skin. The MN assisted $3.9 \mathrm{~N}$ and $7.9 \mathrm{~N}$ delivery of lidocaine horizontally in VE layer are the most favourable regimens. This favourability was due to lidocaine permeating at $100 \mu \mathrm{g} / \mathrm{g}$ and higher from 0.25 till 0.75 hours.

\section{References}

[1] Smith DW, Peterson MR, DeBerard SC. Regional anesthesia: nerve blocks of the extremities and face. Postgrad Med 1999; 106: 69-73.

[2] Quinn RH, Wedmore I, Johnson E, Islas A, Anglim A, Zafren K, Bitter C, Mazzorana V Wilderness medical society practice guidelines for basic wound management in the austere environment. Wild Environ Med 2014; 25: 295-310.

[3] Nir Y, Paz A, Sabo E, Potasman I. Fear of Injections in Young Adults: Prevalence and Associations. Am J Trop Med Hyg 2003; 68: 341-344.

[4] Kim NW, Lee MS, Kim KR, Lee JE, Park JS, Matsumoto Y, Jo DG, Lee H, Lee DS, Jeong $\mathrm{JH}$. Polyplex-releasing microneedles for enhanced cutaneous delivery of DNA vaccine.

J Control Release 2014; 179: 11-17.

[5] Lidoderm (lidocaine) patch. Current comprehensive medication information about marketed drugs. In: U.S. National library of medicine. Daily Med. 2013. http://dailymed.nlm.nih.gov/dailymed/lookup.cfm?setid=5ffefcdc-ebfa-4dc8-b484719658da9d6d Accessed 13 June, 2014). 
[6] Singh I and Morris AP. Performance of transdermal therapeutic systems: Effects of biological factors. Int J Pharm Invest 2011; 1: 4-9.

[7] Akhtar N. Vesicles: A recently developed novel carrier for enhanced topical drug delivery. Curr Drug Delivery 2014; 11: 87-97.

[8] Sivamani R, Stoeber B, Wu G, Zhai H, Liepmann D, Maibach H. Clinical microneedle injection of methly nicotinate: stratum corneum penetration. Skin Res Technol 2005; 11: 152156.

[9] Allen, M, M Prausnitz, D McAllister, and F Cros. Microneedle Devices and Methods of Manufacture and Use Thereof. United States of America Patent US 6334856 B1. January 1, 2002.

[10] Raphael AP, Meliga SC, Chen X, Fernando GJP, Flain C, Kendall MAF. Depth-Resolved Characterization of diffusion properties within and across minimally-perturbed skin layers. $\mathrm{J}$ Control Release 2013; 166: 87-94.

[11] Nayak A, Das DB Vladisavljević G. Microneedle-assisted permeation of lidocaine carboxymethylcellulose with gelatine co-polymer hydrogel. Pharm Res 2014a; 33: 11701184.

[12] Nayak A, Babla H, Han T, Das DB. Lidocaine carboxymethylcellulose with gelatine copolymer hydrogel delivery by combined microneedle and ultrasound. Drug Deliv 2014b; DOI: $10.3109 / 10717544.2014 .935985$.

[13] Bal S, Kruithof AC, Liebl H, Tomerius M, Bouwstra J, Ladermann H, Meinke M. In vivo visualization of microneedle conduits in human skin using laser scanning microscopy. Laser Phys Lett 2010; 7: 242-246.

[14] Peira E, Turci F, Corazzari I, Chirio D, Battaglia L, Fubini B, Gallarate M. The influence of surface charge and photo-reactivity on skin-permeation enchance property of nano- $\mathrm{TiO}_{2}$ in ex vivo pig skin model under indoor light. Int J Pharm 2014; 467: 90-99.

[15] Zhang Y, Brown K, Siebenaler K, Determan A, Dohmeier D, Hansen K. Development of lidocaine-coated microneedle product for rapid, safe, and prolonged local analgesic action. Pharm Res 2012; 29: 170-177.

[16] Mitragotri S. Modeling skin permeability to hydrophilic and hydrophobic solutes based on four permeation pathways. J Control Release 2003; 86: 69-92.

[17] Bari H. A prolonged release parenteral drug delivery system - An overview. Int J Pharm Sci Rev Res 2010; 3: 1-11.

[18] Olkkola KT, Isohanni MH, Hamunen K, Neuvonen PJ. The effect of erythromycin and fluvoxamine on the pharmacokinetics of intraveneous lidocaine. Anesth Analg 2005; 100 : 1352-1356.

[19] Gudin J. Opioid therapies and cytochrome P450 interactions. J Pain Symptom manage 44: S4-S13 
[20] Johnson ME, Blankschtein D, Langer R. Evaluation of solute permeation through the stratum corneum: Lateral bilayer diffusion as the primary transport mechanism. J Pharm Sci 1997; 86: 1162-1172.

[21] Schwindt DA, Wilhelm KP, Maibach I. Water diffusion characteristics of human stratum corneum at different anatomical sites In Vivo. J Invest Dermatol 1998; 111: 385-389.

[22] Nayak A, Das DB. Potential of biodegradable microneedles as a transdermal delivery vehicle for lidocaine. Biotechnol Lett 2013; 35: 1351-1363.

[23] Cheung K, Tao H, Das DB. Effect of force of microneedle insertion on the permeability of insulin in skin. J Diabetes Sci Technol 2014; 8: 444-452.

[24] Cheung K, Das DB. Microneedles for drug delivery: trends and progress. Drug Deliv 2015; doi: 10.3109/10717544.2014.986309 (In press).

[25] Olatunji O, Igwe CC, Ahmed AS, Alhassan DOA, Asieba GO, Das DB. Microneedles from fish scale biopolymer. J Appl Polym Sci 2014; 131: 1-10

[26] Yeu-Chun K, Park JH, Prausnitz MR. Microneedles for drug and vaccine delivery. Adv Drug Deliver Rev 2012; 64: 1547-1568

[27] Brogden NK, Milewski M, Ghosh P, Hardi L, Crofford LJ, Stinchcomb AL. Diclofenac delays micropore closure following microneedle treatment in human subjects. J Control Release 2012; 163: 220-229.

[28] Goldberg S. 2D PAGE: Sample preparation and fractionation. Volume 1. In: Posch A, editor. Mechanical/Physical methods of cell disruption and tissue homogenization: Part 1. Humana Press; 2008. pp. 10-11.

[29] Akin FJ, Norred WP. Factors affecting measurement of aryl hydrocarbon hydroxylase activity in mouse skin. J Invest Dermatol 1976; 67: 709-712.

[30] Entenman, C T. The preparation of tissue lipid extracts. Lectures of the 1961 short course on newer lipid analyses. J Am Oil Chem Soc 1961: 534-535.

[31] Fligiel SE, Varani J, Datta SC, Kang S, Fisher GJ, Voorhees JJ. Collagen degradation in aged/photodamaged skin In Vivo and after exposure to matrix metalloproteinase-1 In Vitro. Soc Invest Dermatol 2003; 120: 842-848.

[32] Steluti R, Scarmato De Rosa F, Collett J, Tedesco AC, Lopes Badra Bentley MV. Topical glycerol monooleate/propylene glycol formulations enhance 5-aminolevulinic acid in vitro skin delivery and in vivo protophorphyrin IX accumulation in hairless mouse skin. Euro $\mathrm{J}$ Pharm Biopharm 2005; 60: 439-444.

[33] Viglianti BL, Dewhirst MW, Abraham JP, Gorman JM, Sparrow Eph M. Rationalization of thermal injury quantification methods: Applications to skin burns. Burns 2014; 40: 896-902.

[34] Bornstein P, Piez KA. A biochemical study of human skin collagen and the relation between intra and intermolecular cross-linking. J Clin Invest 1964; 43: 1813-1823. 
[35] Liu HY, Li D, Guo SD. Studies on collagen from the skin of channel catfish (Ictalurus punctaus). Food Chem 2007; 101: 621-625.

[36] Nagai T, Arakib Y, Suzukia N. Collagen of the skin of ocellate puffer fish (Takifugu rubripes). Food Chem 2002; 78: 173-177.

[37] Park JH, Lee JW, Kim YC, Prausnitz MR. The effect of heat on skin permeability. Int J Pharm 2008; 359: 94-103.

[38] Milewski M, Paudel KS, Brogden NK, Ghosh P, Banks SL, Hammell DC, Stinchcomb AL. Microneedle-Assisted Percutaneous Delivery of Naltrexone Hydrochrloride in Yucatan Minipig: In Vitro-In Vivo Correlation. Mol Pharm 2013; 10: 3745-3757.

[39] Sobanko JF, Miller CJ, Alster TS. Topical anesthetics for dermatologic procedures: A review. Dermatol Surg 2012; 38: 709-721.

[40] Banerjee S, Siddiqui L, Bhattacharya SS, Kaity S, Ghosh A, Chattopadhyay P, Pandey A, Singh L. Interpenetrating polymer network (IPN) hydrogel microspheres for oral controlled release application. Int J Biol Macromol 2012; 50: 198-206.

[41] Naegel A, Heisig M, Wittum G (2013) Detailed modeling of skin penetration-An overview. Adv Drug Deliver Rev 65: 191-207.

[42] Meyer W, Kacza J, Zschemisch NH, Godynicki S, Seeger J. Observations on the actual structural conditions in the stratum superficiale dermis of porcine ear skin, with special reference to its use as model for human skin. Ann Anat 2007; 189: 143-156.

[43] Gupta J, Park SS, Bondy B Felner El, Prausnitz MR. Infusion pressure and pain during microneedle injection into skin of human subjects. Biomaterials 2011; 32: 6823-6831.

[44] Padmanabhan M, Rahoof TE, Vipin Raj VM, Vivek Krishnan K. Pneumatic stretcher chair device for paralysed patients. IJRET 2014; 3: 546-553.

[45] Singh ND, Banga AK. Controlled delivery of ropinirole hydrochloride through skin using modulated iontophoresis and microneedles. J Drug Target 2013; 21: 354-366.

[46] Kalluri H, Banga AK. Formation and closure of microchannels in skin following microporation. Pharm Res 2011; 28: 82-94.

[47] Swindle M. Porcine integumentary system models: Part 1 - Dermal Toxicology. Sinclair Research Centre 2008.

[48] Lepock JR, Frey HE, Ritchie KP. Protein denaturation in intact hepatocytes and isolated cellular organelles during heat shock. J Cell Biol 1993; 122: 1267-1276.

[49] Wagner H, Kostka KH, Lehr CM, Schaefer UF. Drug distribution in human skin using two different In Vitro test systems: Comparison with In Vivo data. Pharm Res 2000; 17: 14751481

[50] Moser K, Kriwet K, Naik A, Kalia YN, Guy RH. Passive skin penetration enhancement and its quantification in vitro. Euro J Pharm Biopharm 2001; 52: 103-112. 
[51] Ghafari R, Baradari AG, Firouzian A, Nouraei M, Aarabi M, Zamani A, Zeydi AE. Cognitive deficit in first-time coronary artery bypass graft patients: a randomized clinical trial of lidocaine versus procaine hydrochloride. Perfusion 2012; 27: 320-325.

[52] Liu P, Bergstrom TK. Quantitative evaluation of aqueous isopropyl alcohol enhancement on skin flux of terbutaline (Sulfate). 2. Permeability contributions of equilibrated drug species across human skin in vitro. J Pharm Sci 1996; 85: 320-325.

[53] Olatunji O, Das DB, Nassehi V. Modelling transdermal drug delivery using microneedles. J Pharm Sci 2012; 101: 164-175.

[54] British, Standards. ISO 5725-2. International Standard, Standards Board, 2002.

[55] Woodruff C, Wieczorek PM, Schricker T, Vinet B, Backman SB. Atomised lidocaine for airway topical anaesthesia in the morbidly obese: $1 \%$ compared with $2 \%$. Anaesthesia 2010; 65: 12-17. 


\section{List of Figures}
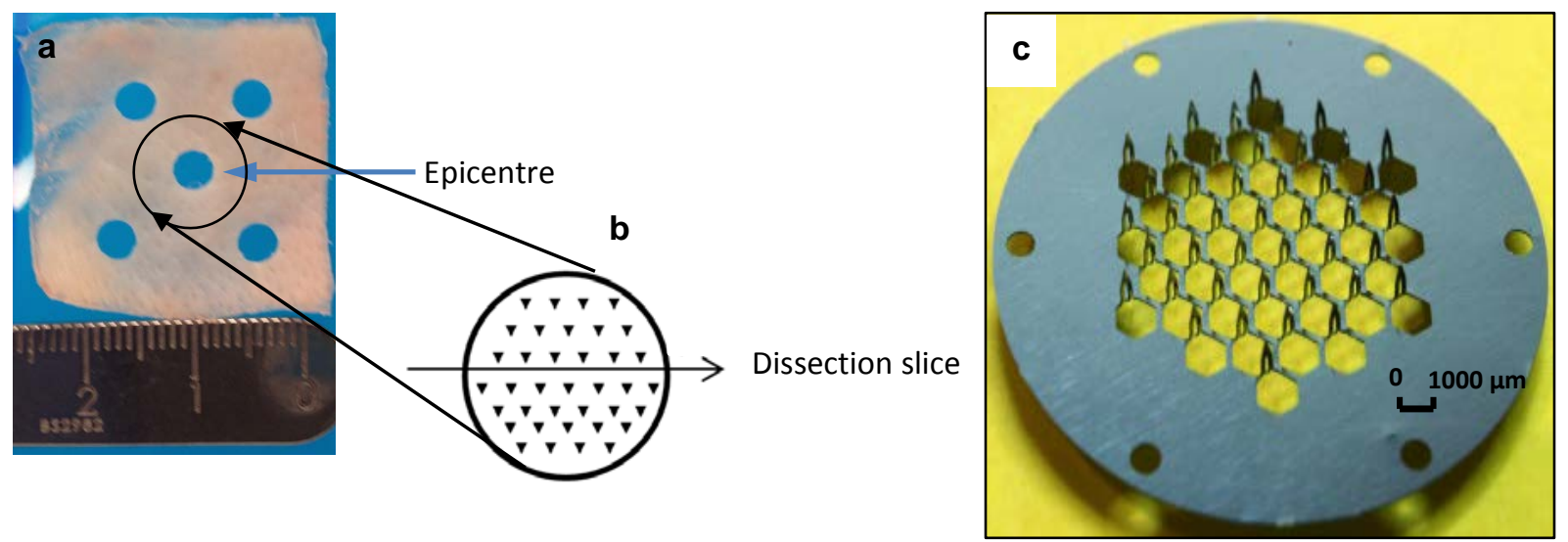

Figure 1. Schematic diagram to show (a) the epicentre punch where the blue circle shows the area/size of the chosen microneedle patch, (b) the orientation of microneedle imprints in obtaining a slice in quantifying microcavity pathlengths, (c) prefabricated microneedles adopted (AdminPatch ${ }^{\circledR}$, Sunnyvale, USA) for 'poke and patch' drug delivery in this work. 


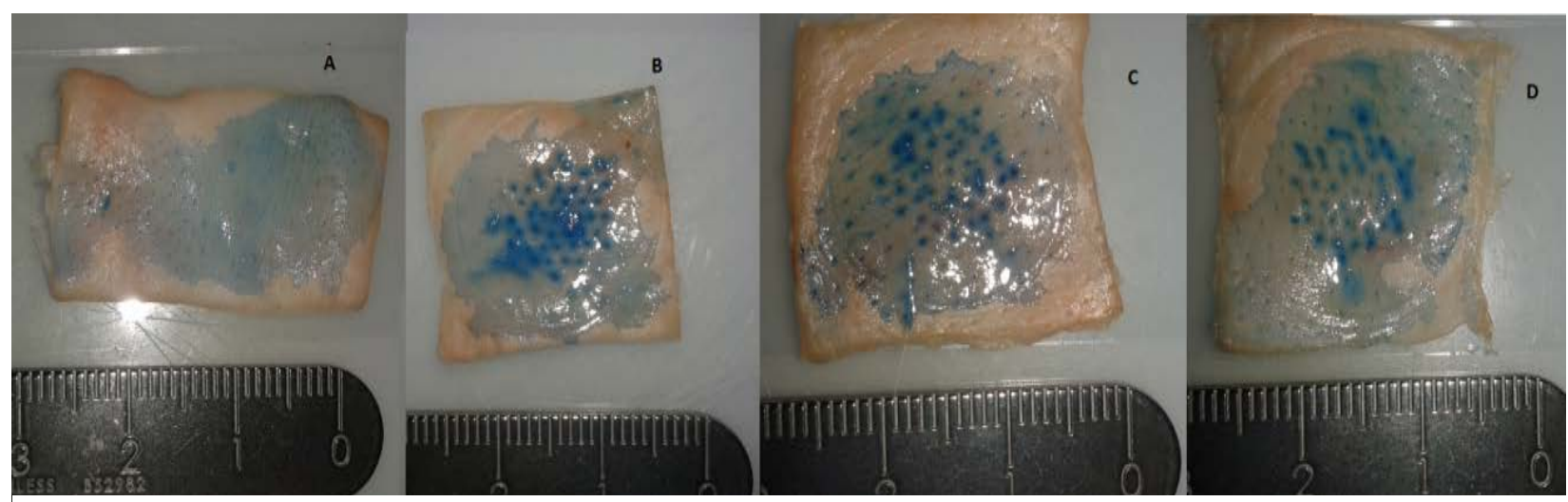

Figure 2. Typical surface images of $(A)$ non-treated skin sample, (B) MN treated skin with insertion force of $3.9 \mathrm{~N},(\mathrm{C}) \mathrm{MN}$ treated skin with insertion force of $7.9 \mathrm{~N}$, (D) MN treated skin with insertion force of $15.7 \mathrm{~N}$, all after a constant application time of $5 \mathrm{~min}$. The dye (blue colour) is from Spirulina used in food colouring (Sainbury's, Loughborough, Leicestershire, UK). 

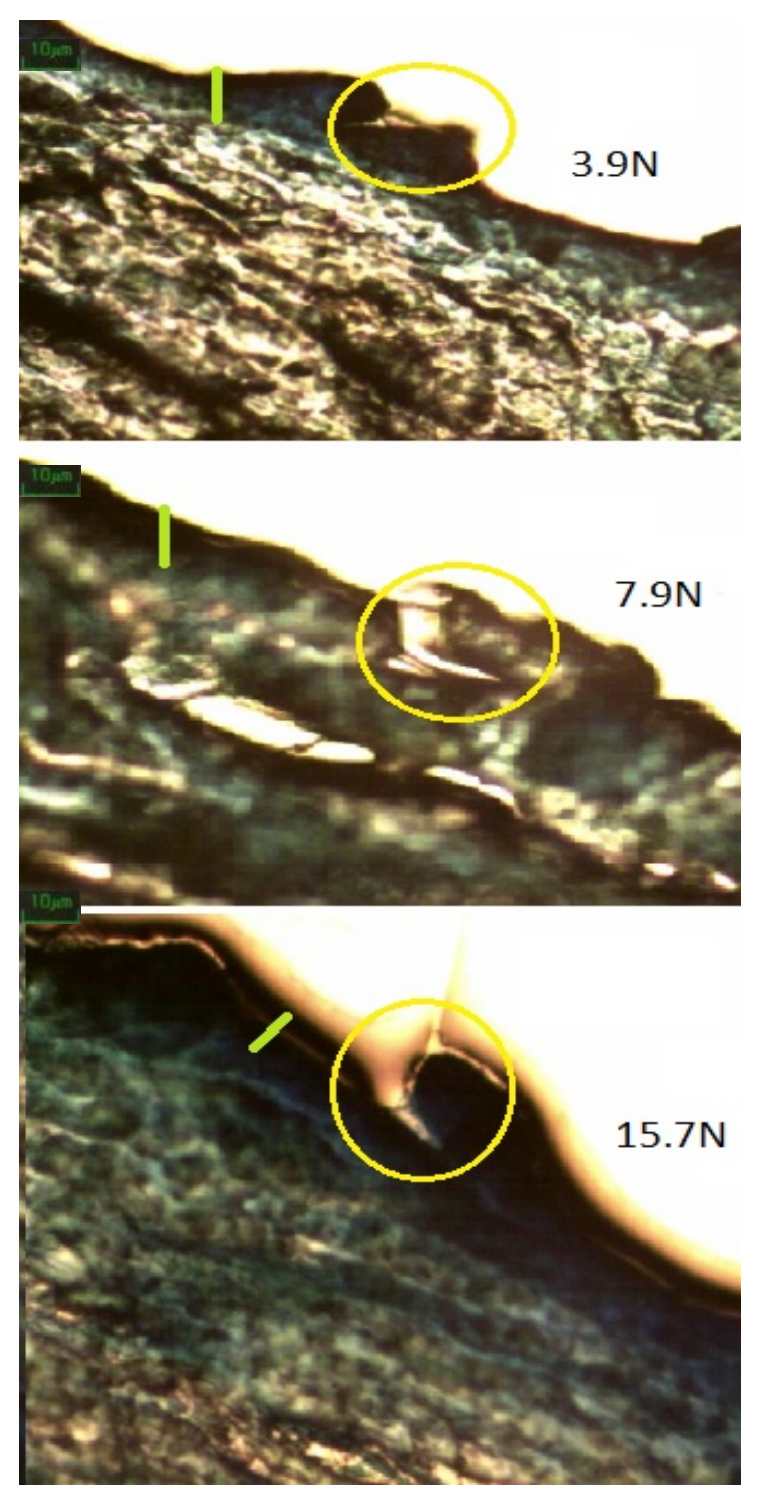

Figure 3: Typical microscope images of MN cavities (yellow circle) in micro-dissected skin for different MN insertion forces. 


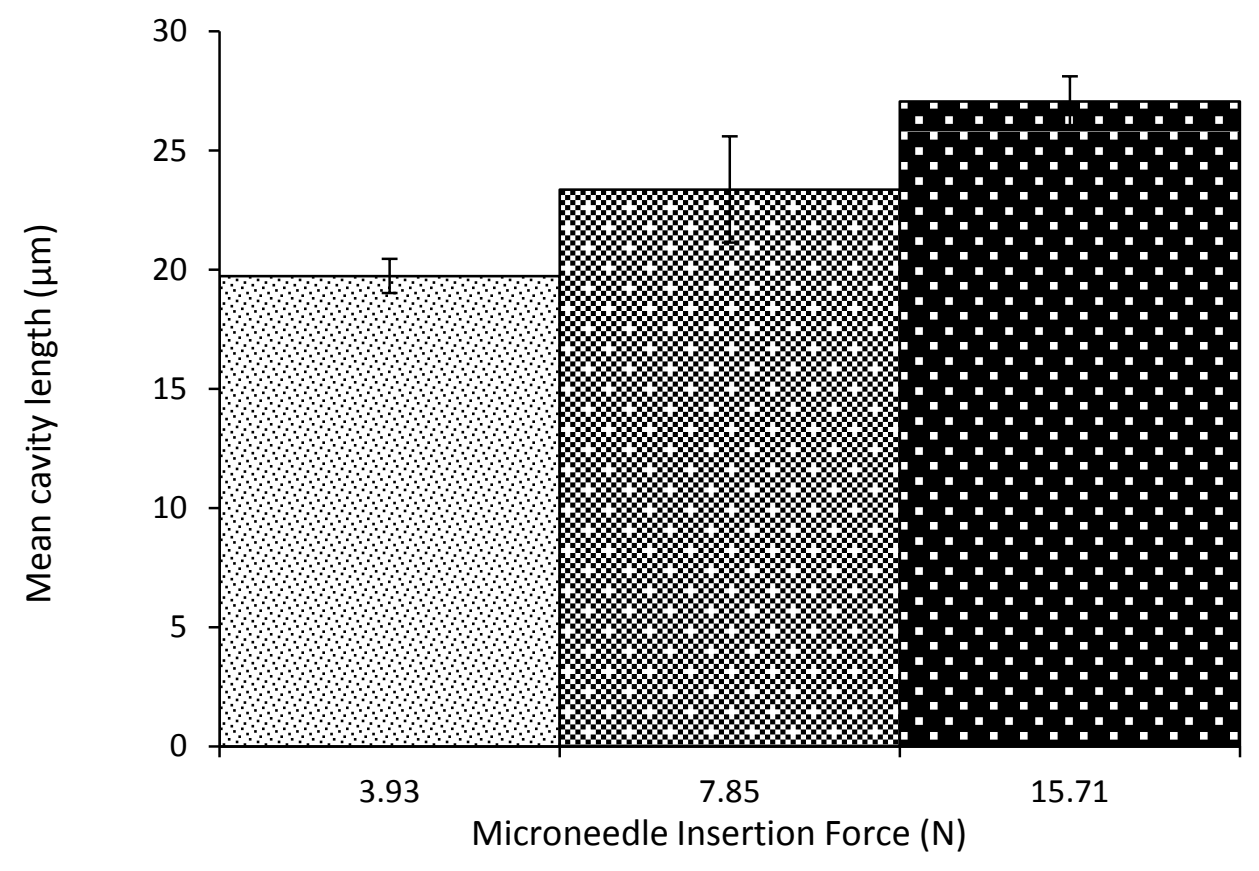

Figure 4: Average lengths of MN cavity in skin for different MN insertion forces ( $n=6$ per force). The results show that the cavity lengths are slightly bigger than the top layer of the skin (stratum corneum). These are relevant for percutaneous delivery of lidocaine. 


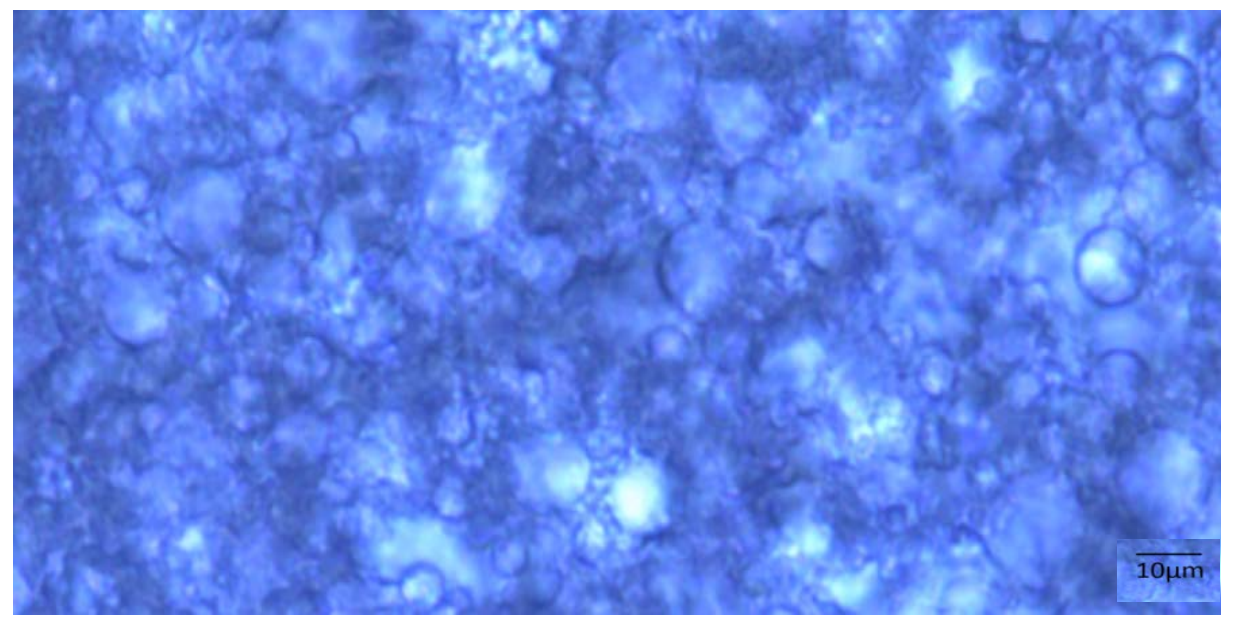

Figure 5: Lidocaine NaCMC/GEL 1:2.3 microgel microparticles 

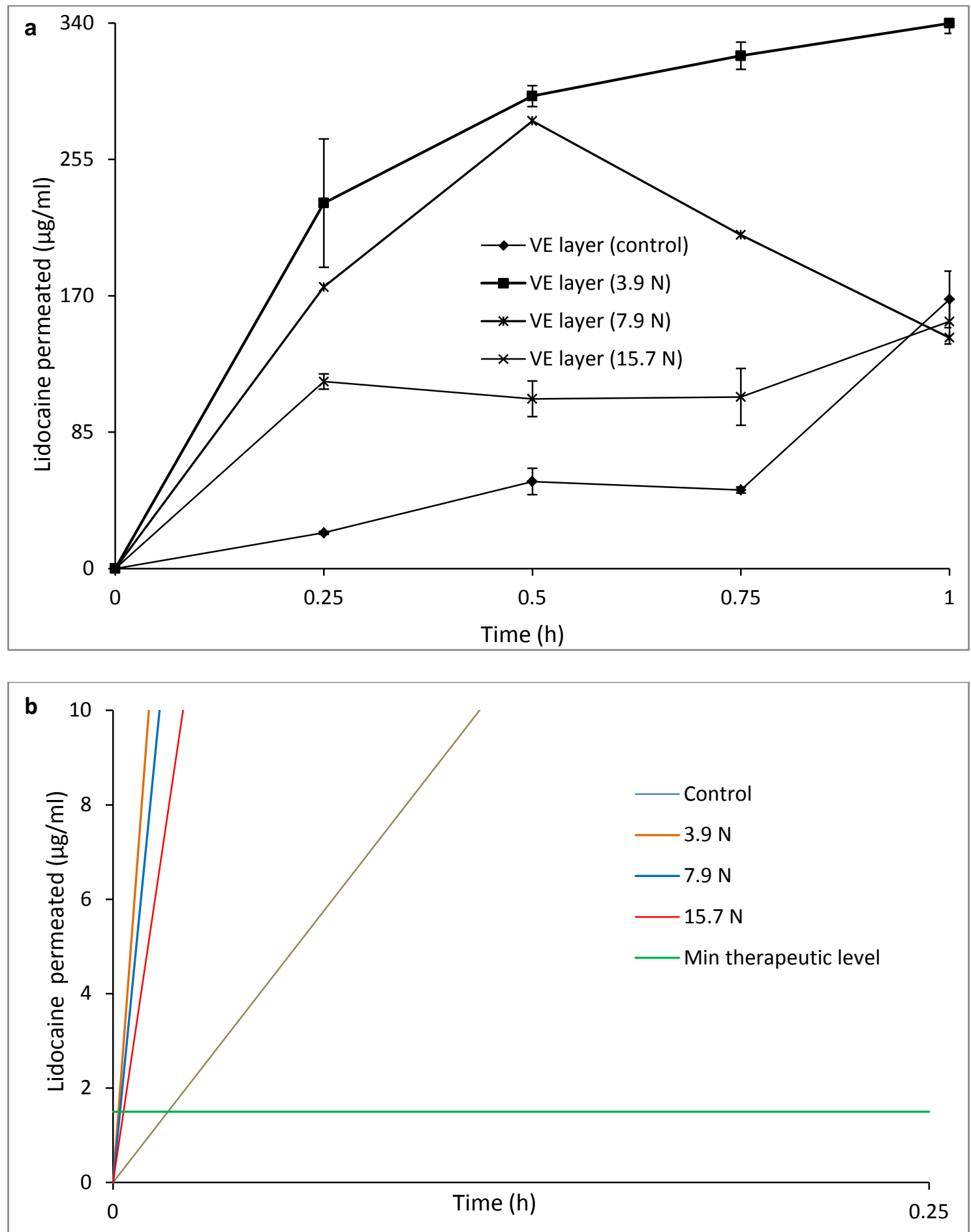

Figure 6 Lidocaine permeated into VE skin layer vertically a) control and microneedle pierced skin at given force induced depths b) control and microneedle pierced skin crossing the minimum therapeutic level for lidocaine before $0.25 \mathrm{~h}$. 


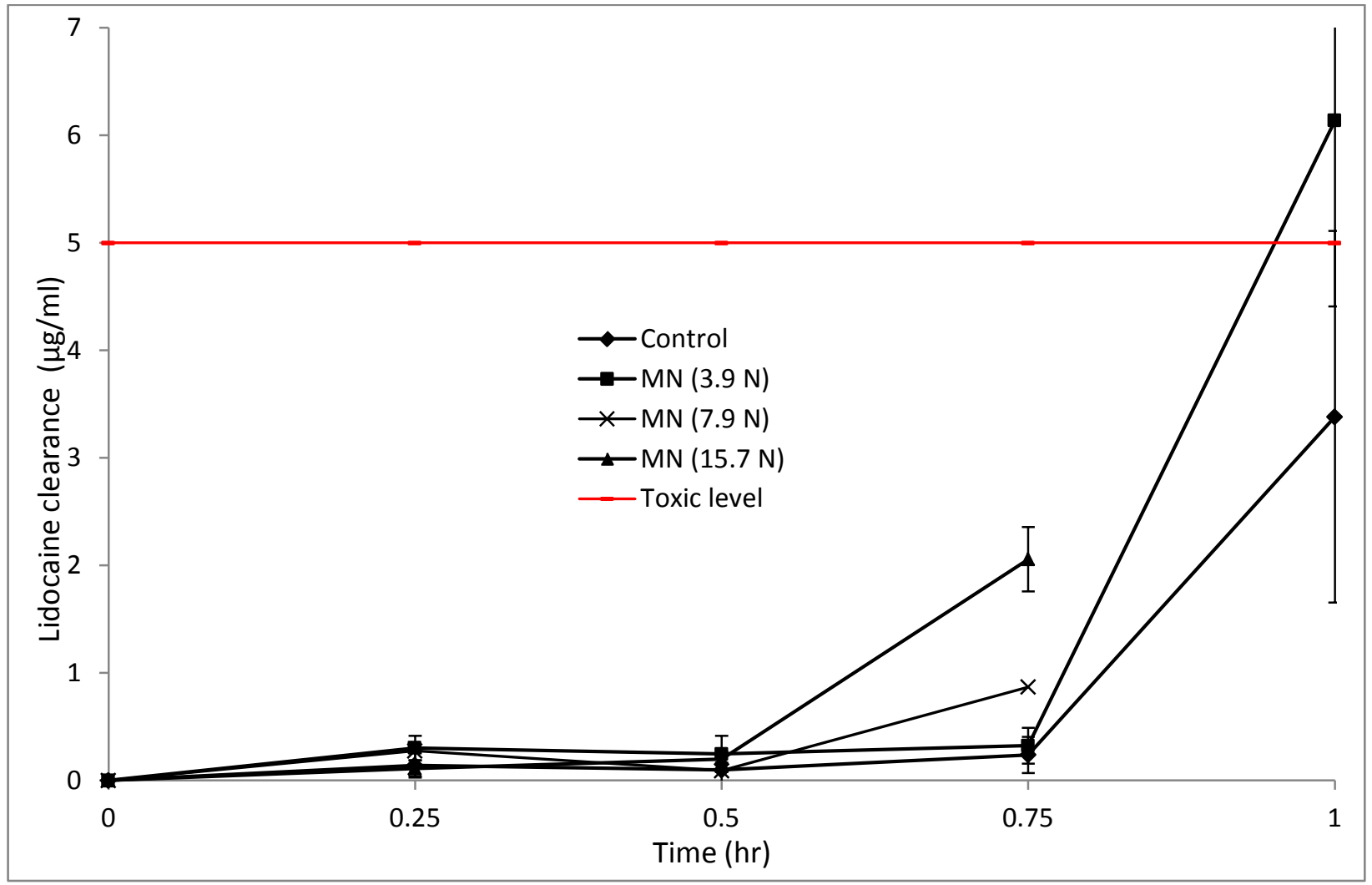

Figure 7 Lidocaine clearance in control, microneedle treated skin forces (3.9 to $15.7 \mathrm{~N}$ ) and the toxic level for lidocaine in plasma clearance concentration. 


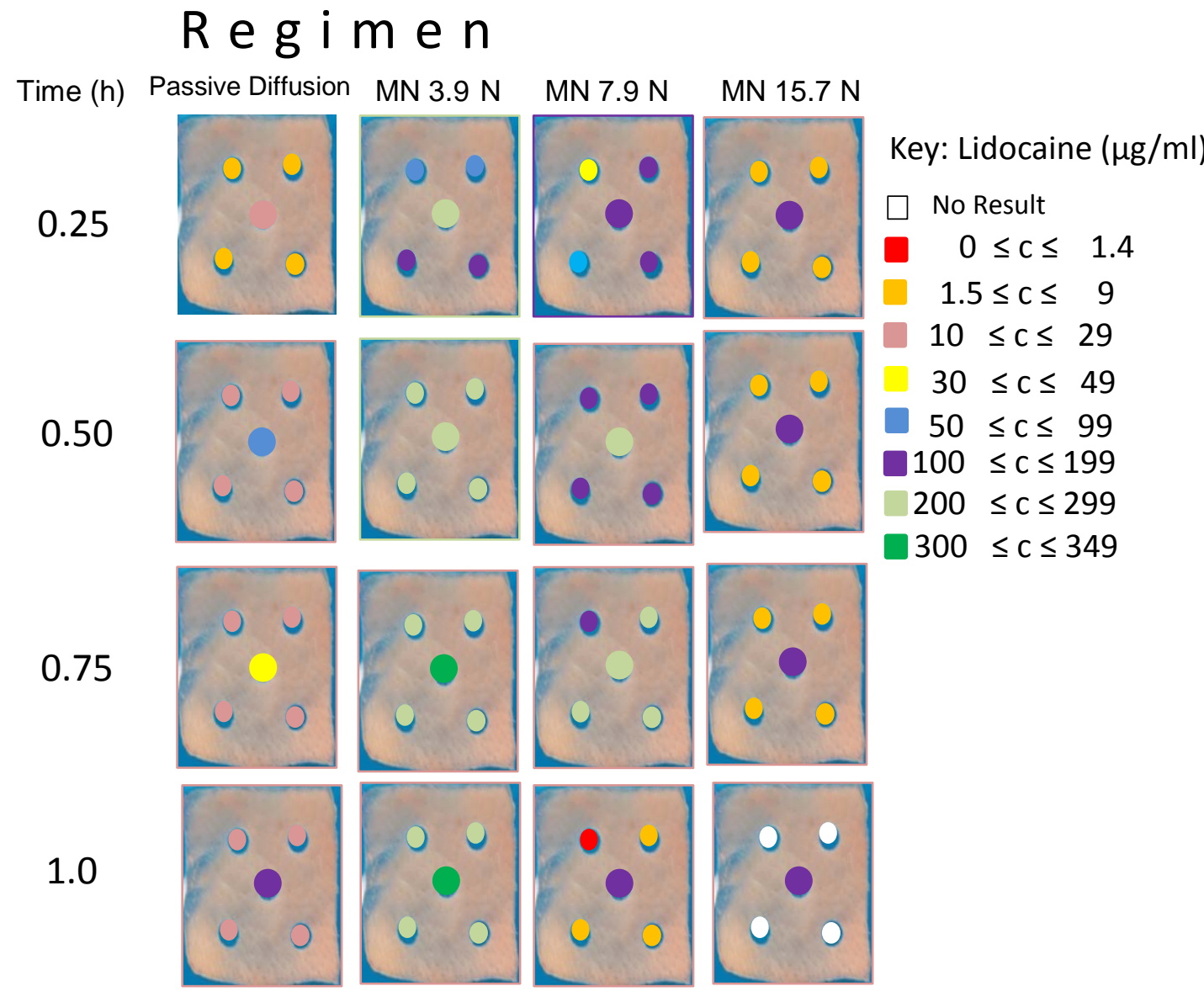

Figure 8. Colour codes to outline the local area and distance for drug permeation (horizontal) in the VE layer of skin according to concentration of lidocaine. 


\section{R e g i m e $n$}

Time (h) Passive Diffusion $\mathrm{MN} 3.9 \mathrm{~N}$

MN 7.9 N MN $15.7 \mathrm{~N}$

0.25
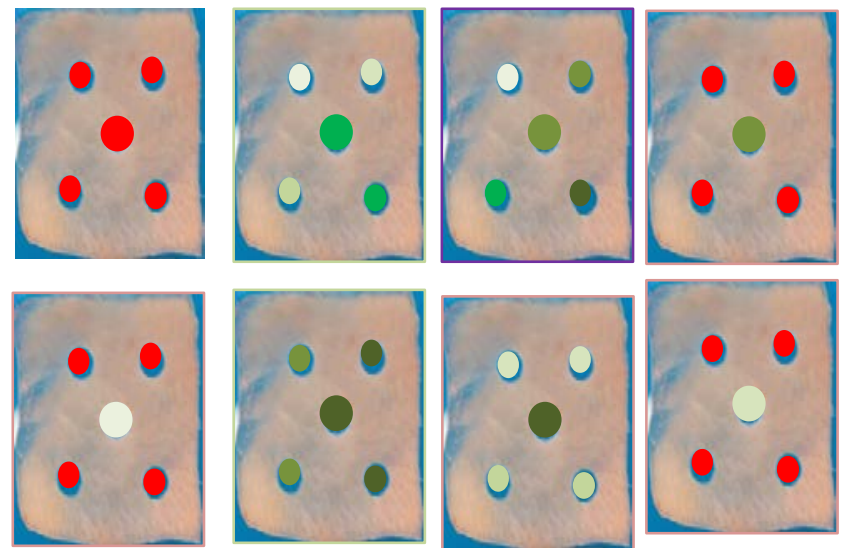

Key: Lidocaine $(\mu \mathrm{g} / \mathrm{g})$

0.50

0.75
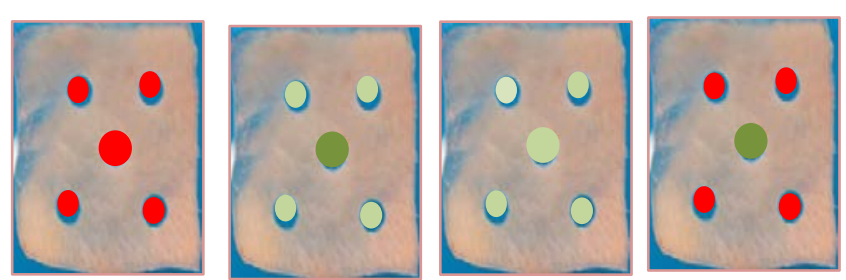

$\begin{aligned} & \text { No Result } \\ 0 & \leq \mathrm{c} \leq 49 \\ 50 & \leq \mathrm{c} \leq 99 \\ 100 & \leq \mathrm{c} \leq 199\end{aligned}$

$200 \leq \mathrm{c} \leq 299$

$300 \leq \mathrm{c} \leq 399$

$400 \leq c \leq 499$

$500 \leq c \leq 699$

$700 \leq \mathrm{c} \leq 899$

1.0
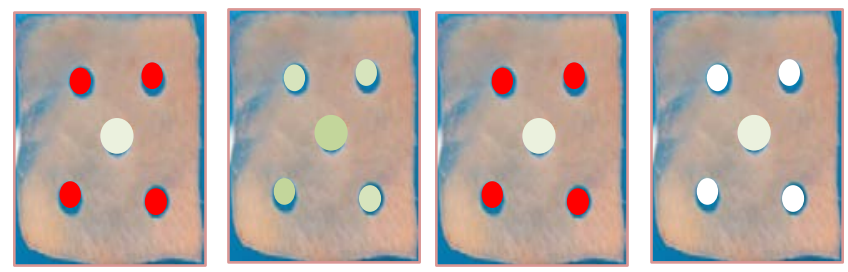

Figure 9. Coloured contrast circles to outline the local area and distance for drug permeation (horizontal) in the VE layer of skin according to the mass of lidocaine 


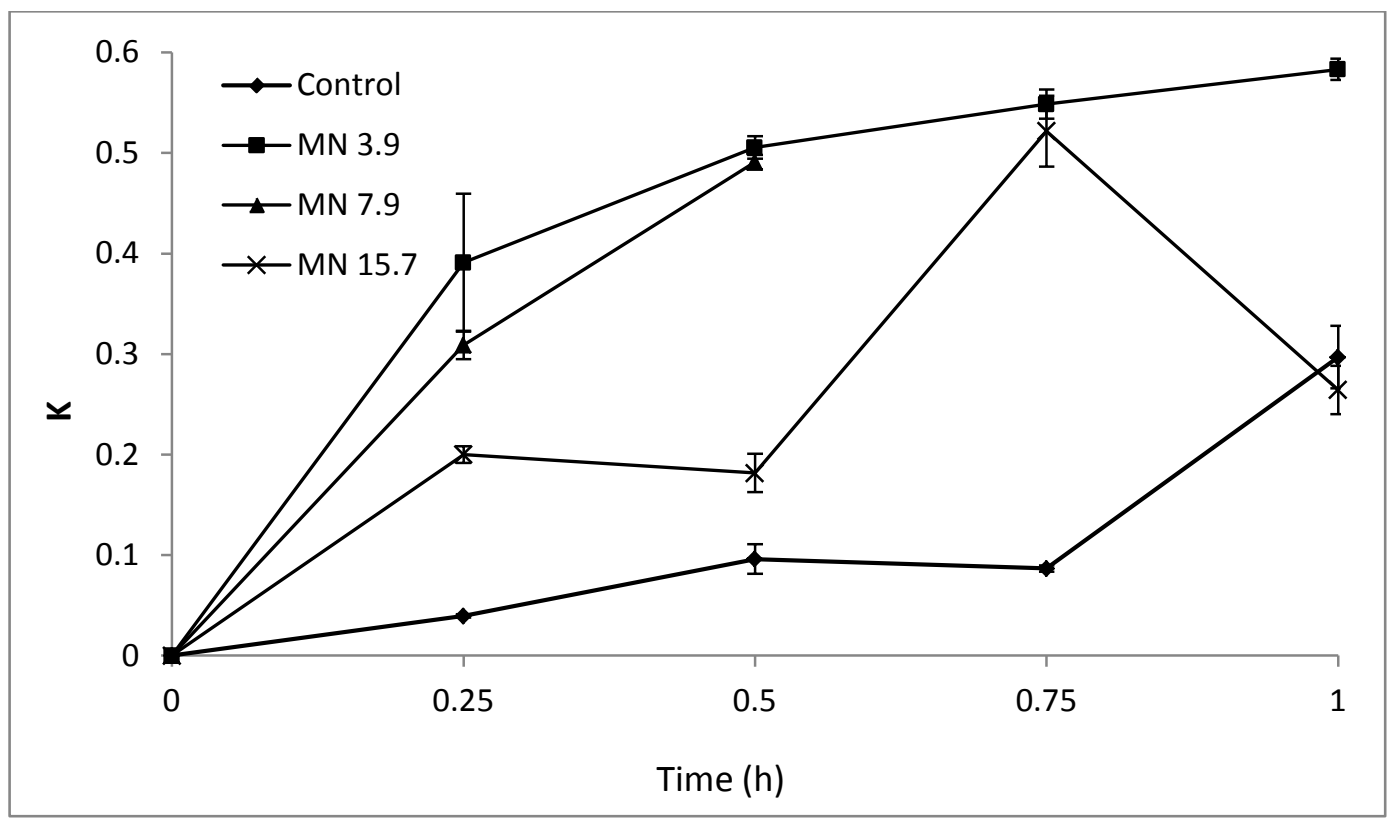

Figure 10. The partition coefficient $(K)$ of lidocaine between vehicle and VE layer 

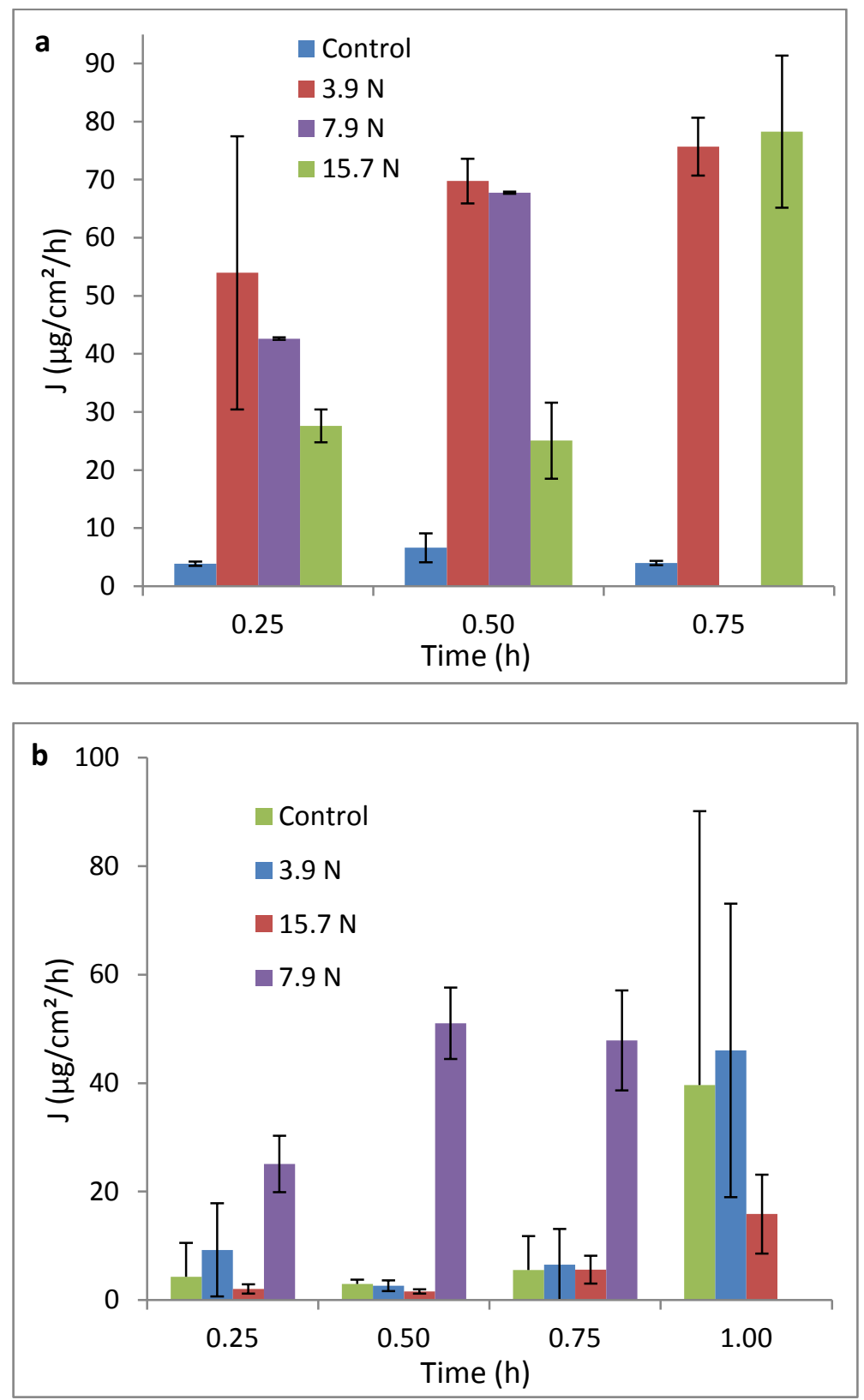

Figure 11. The permeation flux of lidocaine in (a) VE skin layer (b) clearance compartment (receptor cell in Franz diffusion cell) 


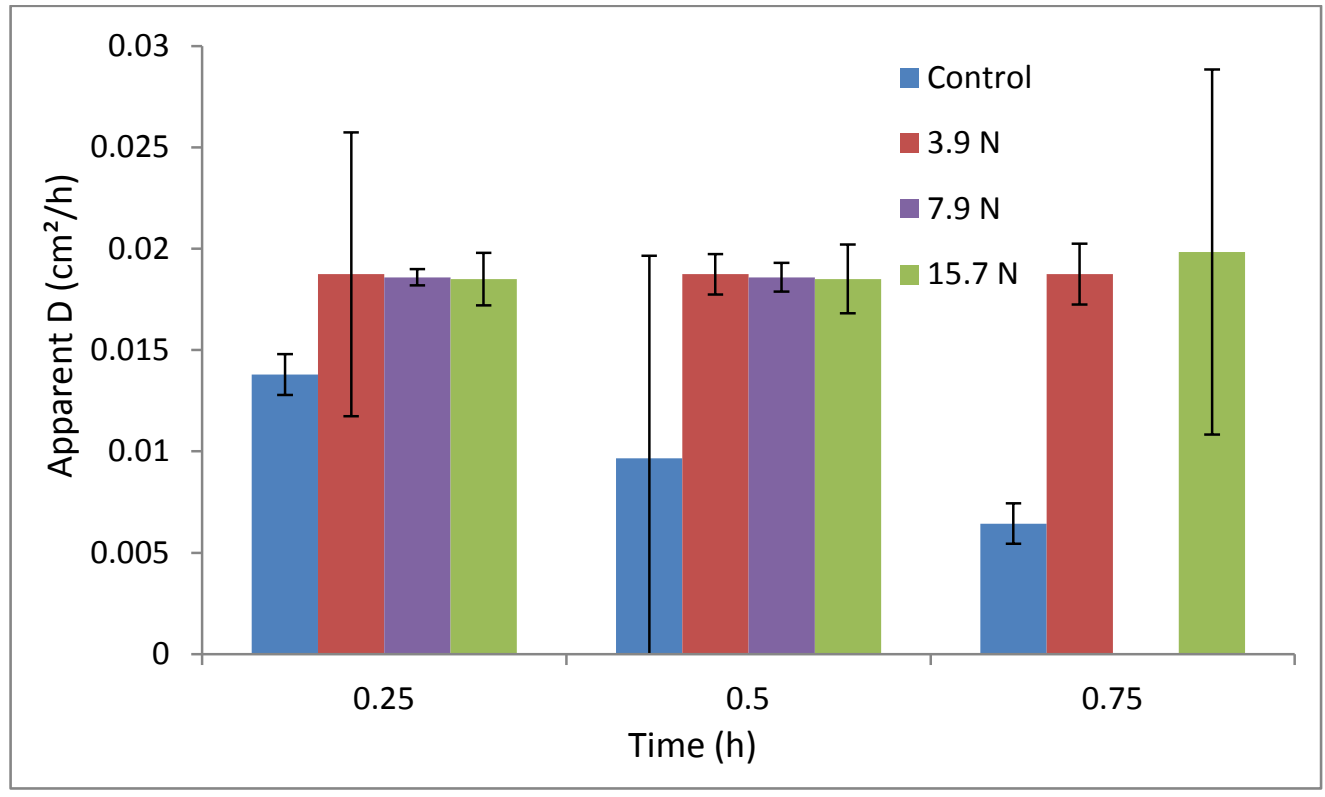

Figure 12. The apparent diffusion coefficients of lidocaine (vertical permeation) 